\title{
The mechanism of acquired resistance to irreversible EGFR tyrosine kinase inhibitor-afatinib in lung adenocarcinoma patients
}

\author{
Shang-Gin Wu ${ }^{1,2}$, Yi-Nan Liư ${ }^{3}$, Meng-Feng Tsai ${ }^{4}$, Yih-Leong Chang ${ }^{5}$, Chong-Jen $\mathrm{Yu}^{2,3}$, \\ Pan-Chyr Yang ${ }^{2,3}$, James Chih-Hsin Yang ${ }^{6}$, Yueh-Feng Wen7, Jin-Yuan Shih ${ }^{2,3}$ \\ ${ }^{1}$ Department of Internal Medicine, National Taiwan University Hospital Yun-Lin Branch, Yun-Lin, Taiwan \\ ${ }^{2}$ Graduate Institute of Clinical Medicine, College of Medicine, National Taiwan University, Taipei, Taiwan \\ ${ }^{3}$ Department of Internal Medicine, National Taiwan University Hospital, and College of Medicine, National Taiwan University, \\ Taipei, Taiwan \\ ${ }^{4}$ Department of Molecular Biotechnology, Da-Yeh University, Chang-Hua, Taiwan \\ ${ }^{5}$ Department of Pathology, National Taiwan University Hospital, College of Medicine, National Taiwan University, Taipei, \\ Taiwan \\ ${ }^{6}$ Department of Oncology, National Taiwan University Hospital, and Graduate Institute of Oncology, Cancer Research Center, \\ National Taiwan University, Taipei, Taiwan \\ ${ }^{7}$ Department of Internal Medicine, National Taiwan University Hospital Hsinchu Branch, Hsinchu, Taiwan \\ Correspondence to: Jin-Yuan Shih, e-mail: jyshih@ntu.edu.tw
}

Keywords: lung adenocarcinoma, afatinib, T790M, acquired resistance, EGFR TKI

Received: October 08, 2015

Accepted: January 23, 2016

Published: February 04, 2016

\section{ABSTRACT}

Introduction: Epidermal growth factor receptor (EGFR) tyrosine kinase inhibitors (TKIs) are associated with favorable response in EGFR mutant lung cancer. Acquired resistance to reversible EGFR TKIs remains a significant barrier, and acquired EGFR T790M-mutation is the major mechanism. Second-generation irreversible EGFR TKI, afatinib, had also been approved for treating EGFR mutant lung cancer patients, but the mechanism of acquired resistance to afatinib has not been well studied.

Results: Forty-two patients had tissue specimens taken after acquiring resistance to afatinib. The sensitizing EGFR mutation were all consistent between pre- and postafatinib tissues. Twenty patients $(47.6 \%)$ had acquired T790M mutation. T790M rate was not different between first-generation EGFR TKI-naïve patients (50\%) and first-generation EGFR TKI-treated patients $(46.4 \%)(p=0.827)$. No clinical characteristics or EGFR mutation types were associated with the development of acquired T790M. No other second-site EGFR mutations were detected. There were no small cell or squamous cell lung cancer transformation. Other genetic mutations were not identified in PIK3CA, BRAF, HER2, KRAS, NRAS, MEK1, AKT2, LKB1 and JAK2.

Methods: Afatinib-prescription record of our department of pharmacy from January 2007 and December 2014 was retrieved. We investigated patients with tissue specimens available after acquiring resistance to afatinib. Enrolled patients should have partial response or durable stable disease of treatment response to afatinib. Various mechanisms of acquired resistance to first-generation EGFR TKIs were evaluated. Histology and cytology were reviewed. EGFR, PIK3CA, BRAF, HER2, KRAS, NRAS, MEK1, AKT2, LKB1 and JAK2 genetic alterations were evaluated by sequencing. Statistical analysis was performed using Chi-square test and Kaplan-Meier method.

Conclusions: T790M was detected in half of the lung adenocarcinoma after acquiring resistance to afatinib. T790M is still the major acquired resistance mechanism. First-generation EGFR TKI exposure did not influence the prevalence of T790M in lung cancer acquired resistance to afatinib. 


\section{INTRODUCTION}

Lung cancer is a leading cause of cancer-related mortality worldwide [1]. Use of epidermal growth factor receptor tyrosine kinase inhibitors (EGFR TKI) produces dramatic response and favorable prognosis in patients with lung adenocarcinoma harboring epidermal growth factor receptor $(E G F R)$ mutations, especially exon 19 deletion and exon 21 L858R point mutations [2]. First-generation EGFR TKIs consisted of gefitinib and erlotinib, which reversibly bind to EGFR and block EGFR signaling. Several phase III trials had proven the effect and benefit of the use gefitinib and erlotinib as first-line agents [3-5].

Second-generation EGFR TKI, afatinib, is an irreversible EGFR TKI which has more potent EGFR inhibition and targets other ErbB-family members. According to LUX-Lung 3 and LUX-Lung 6 studies, afatinib had a significant better response rate and prolonged progression-free survival (PFS) as compared with pemetrexed plus cisplatin or gemcitabine plus cisplatin in patients with treatment-naïve advanced lung adenocarcinoma harboring activating $E G F R$ mutations $[6,7]$. Afatinib as first-line treatment even prolongs overall survival in patients with exon 19 deletion [8].

However, patients with EGFR mutant lung cancer develop disease progression after a median of 10 to 14 months on EGFR TKI. Different mechanisms of acquired resistance to first-generation EGFR TKIs had been reported $[9,10]$. Acquired T790M was the major mechanism of acquired resistance to first-generation EGFR TKIs, and it accounts for about a half of the cases with acquired resistance to gefitinib or erlotinib. Several third-generation EGFR TKIs, which irreversibly block T790M mutant EGFR, have shown to be effective in patients with acquired $E G F R$ mutant lung cancer patients who acquired T790M after treatment failure with previous EGFR TKIs [11, 12]. In addition, other acquired resistance mechanism has been reported; including the development of small cell lung cancer or squamous cell transformation, second point mutations (D761Y or L747S), MET amplification, acquired PIK3CA or BRAF mutation, and epithelial-to-mesenchymal transition $[9,10,13-16]$.

Although a preclinical study showed that afatinib could inhibit EGFR T790M and block the growth of non-small cell lung cancer (NSCLC) cell lines harboring T790M mutations [17], the clinical trial did not show the overall survival benefit in patients after failure of platinum doublet and first-generation EGFR TKIs [18]. The emergence of acquired resistance remains a significant barrier for afatinib-treated patient in clinical practice. There was only one case report that showed the detection of acquired T790M in lung cancer cells after the development of resistance to afatinib [19]. However, the prevalence of T790M in lung cancer patients with acquired resistance to afatinib has not been studied. In vitro, fibroblast growth factor receptor 1 (FGFRl) activation was reported as an escape mechanism in human lung cancer cells resistant to afatinib [20]. The other gene mutations and histological evolution of lung cancers after acquiring resistance to afatinib remained poorly understood.

In this study, we explore the prevalence of different acquired resistance mechanisms in tissue specimens taken from patients with acquired resistance to afatinib.

\section{RESULTS}

\section{Patient collection}

From January 2007 to December 2014, there were 518 patients who had taken afatinib according to the afatinib-prescription record from the department of pharmacy, NTUH. Those whose lung cancer harboring TKI-sensitive mutations with partial response or durable stable disease (PFS $\geq 6$ months) under afatinib treatment and having post-afatinib tissue specimen collected for analysis were enrolled. We enrolled 42 patients in this study (Figure 1).

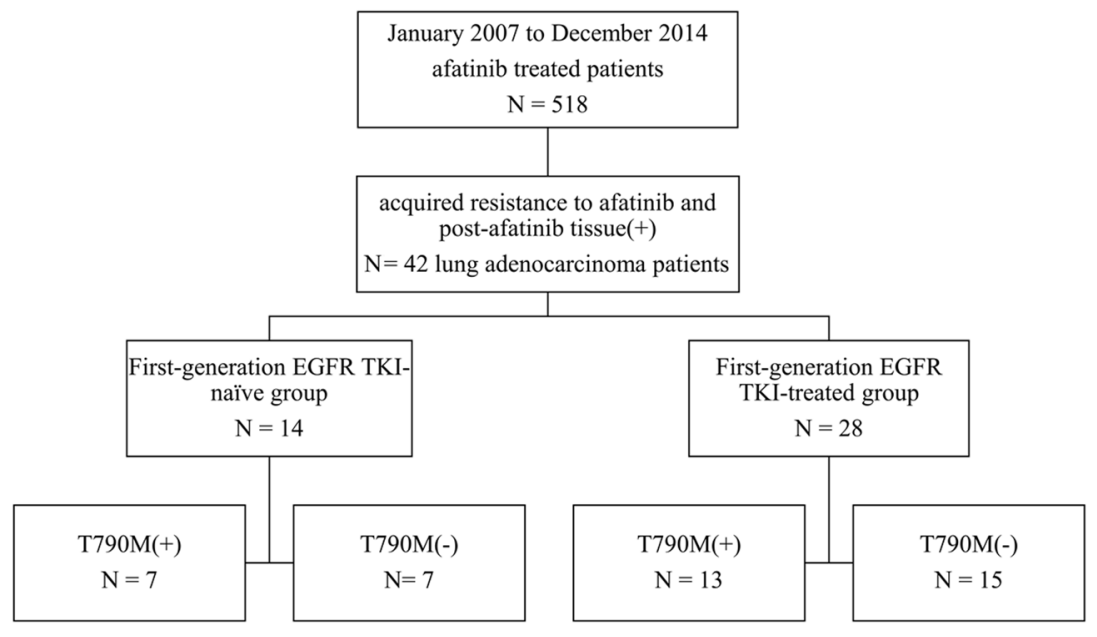

Figure 1: Patient collection flow chart. 
Of the 42 patients, there were 25 females $(59.5 \%)$ and 33 never smokers (78.6\%). All of them had EGFR mutation reports before afatinib treatments, including: 14 deletions in exon-19, 22 L858R and 6 other EGFR mutations (L861Q, D770_N711 dupSVD, G719S + S768I, G719C + S768I, L858R + E709G, L858R + S768I). Treatment responses of afatinib were 37 partial response and 5 stable disease (Table 1). Fourteen patients were first-generation EGFR TKI-naïve patients. Twenty-eight patients belonged to first-generation EGFR TKI-treated group, and they received prior first-generation EGFR TKIs treatment before taking afatinib, including: 5 gefitinib, 9 erlotinib, and 14 gefitinib and erlotinib.

The specimens of acquired resistance came from different sites, and the majority was lung tissue via computed tomography or echo-guided biopsy or malignant pleural effusions (MPEs) via thoracentesis. The details of rebiopsy sites and procedure were described in Table 2.

\section{T790M prevalence of acquired resistance to afatinib in lung adenocarcinoma patients}

The specimens with acquired resistance to afatinib all showed the same sensitizing EGFR mutations as the paired treatment-naïve or pre-afatinib treatments tissue specimens. We detected a second-site T790M-EGFR mutation in $20(47.6 \%)$ of the 42 specimens with acquired resistance to afatinib, including: 8 MPEs (44.4\%) and 12 lung tissues (63.2\%) (Table 2). We did not detect other secondary substitutions or point mutation of EGFR, including D761Y, L747S and C797S.

Of the 20 patients with acquired T790M, there were 7 from $14(50.0 \%)$ first-generation EGFR TKI-naïve group and 13 from 28 (46.4\%) first-generation EGFR TKI-treated group ( $p=0.827)$. The sensitizing EGFR mutation types of the 20 tumors with acquired T790M included 9 deletion in exon-19 (64.3\%; 9 of 14), 10 L858R (45.5\%; 10 of 22) and one L861Q (16.7\%; 1 of 6$)$ $(p=0.142)$. The clinical factors, including age, smoking, sex, afatinib treatment response, prior first-generation EGFR TKI use were not associated with the detection of T790M after acquired resistance to afatinib (Table 3).

\section{Other genetic mutation after acquired resistance to afatinib}

The afatinib resistant specimens were examined for histological transformation or genetic mutations. All specimens with acquired resistance to afatinib showed adenocarcinoma. There were no small cell lung cancer or squamous cell transformations.

Because of the limited amount of available specimens, we cannot analyze all possible genes in all samples. The sample numbers for gene mutation analysis were 26 for PIK3CA, 25 for HER2, 26 for $B R A F, 26$ for $K R A S, 24$ for NRAS, 26 for $M E K 1,24$ for $A K T 2,20$ for
$J A K 2$ and 18 for $L K B 1$. We did not identify any genetic alternation $(0 \%)$ in these genes.

\section{Progression-free survival and post-progression survival of afatinib}

Of the 42 patients with acquired resistance to afatinib, there was no difference in PFS following afatinib treatment between patients with and without acquired T790Mmutations (median, 8.9 months vs. 8.2 months; $p=0.938$ ) (Figure 2A). First-generation EGFR TKI exposure had influence on PFS of afatinib. The difference in PFS of afatinib reached a statistical significance between 14 firstgeneration EGFR TKI-naïve and 28 first-generation EGFR TKI-treated patients (median, 21.0 months vs. 7.0 months; $p<0.001$ ) (Figure 2B).

To clarify the effect of afatinib, we focused on the 14 first-generation EGFR TKI-naïve patients. PFS were 21.0 months in patients with acquired T790M and 33.8 months in patients without acquired T790M $(p=0.648)$ (Figure 3A). Although patients with acquired T790M had longer median post-afatinib-progression survival (35.3 months) than patients without acquired T790M mutations (17.8 months), the difference did not reach statistical significance $(p=0.616)$ (Figure $3 \mathrm{~B})$.

\section{DISCUSSION}

The study showed that approximately half of lung cancer patients with acquired resistance to afatinib had a second EGFR T790M mutation. Acquired T790M mutation is still the most common mechanism of acquired resistance to afatinib, a second-generation EGFR TKI. The prevalence of acquired T790M were similar in patients with and without prior exposure to first-generation EGFR TKI. Other acquired resistance mechanisms, including small cell lung cancer or squamous cell transformation, mutation in PIK3CA, BRAF, HER2, KRAS, NRAS, MEK1, $A K T 2, L K B 1$ and $J A K 2$, were not detected.

Of the acquired resistance mechanisms of firstgeneration EGFR TKIs, acquired T790M, was found in approximately $50-60 \%$ of EGFR-mutant resistance cases [21-23]. The present study showed that acquired T790M in $47.6 \%$ of the specimens with acquired resistance to afatinib. This is compatible with prior studies about acquired resistance to first-generation EGFR TKI. In addition, our study showed that the prevalence of T790M in the tissue samples with acquired resistance to afatinib was not different whether patients took firstgeneration EGFR TKIs before afatinib or not. This may result from that we only enrolled those with partial response or durable stable disease to afatinib. Acquired T790M formation is still the main mechanism of acquired resistance to afatinib.

In addition to $\mathrm{T} 790 \mathrm{M}$, other acquired EGFR mutations to first-generation EGFR TKIs, including 
Table 1: Clinical characteristics of lung adenocarcinoma patients with acquired resistance to afatinib

\begin{tabular}{|c|c|c|c|}
\hline & & $\begin{array}{c}\text { All } \\
\text { patients }\end{array}$ & $(\%)$ \\
\hline \multicolumn{2}{|l|}{ Total No. } & 42 & $(100)$ \\
\hline \multicolumn{2}{|l|}{ Age, median years } & 57.5 & \\
\hline \multicolumn{2}{|l|}{ (range) } & $(35.2-81.1)$ & \\
\hline \multicolumn{4}{|l|}{ Sex } \\
\hline & Female & 25 & $(59.5)$ \\
\hline & Male & 17 & $(40.5)$ \\
\hline \multicolumn{4}{|l|}{ Smoking } \\
\hline & Never-smokers & 33 & (78.6) \\
\hline & Smokers & 9 & $(21.4)$ \\
\hline \multicolumn{4}{|l|}{ EGFR mutation } \\
\hline & Del-19 & 14 & $(33.3)$ \\
\hline & L858R & 22 & $(52.4)$ \\
\hline & Other & 6 & $(14.3)$ \\
\hline \multicolumn{4}{|l|}{ Pre-afatinib } \\
\hline & TKI-naïve & 14 & (33.3) \\
\hline & TKI using & 28 & $(66.7)$ \\
\hline & Gefitinib & 5 & \\
\hline & Erlotinib & 9 & \\
\hline & Gefitinib and Erlotinib & 14 & \\
\hline \multicolumn{4}{|l|}{ Line of afatinib } \\
\hline & 1 & 7 & $(16.7)$ \\
\hline & 2 & 7 & $(16.7)$ \\
\hline & 3 & 3 & (7.1) \\
\hline & $\geq 4$ & 25 & $(59.5)$ \\
\hline \multicolumn{4}{|l|}{ Afatinib response } \\
\hline & PR & 37 & $(88.1)$ \\
\hline & SD & 5 & $(11.9)$ \\
\hline
\end{tabular}

EGFR: epidermal growth factor receptor, Del-19: deletion in exon 19, TKI: tyrosine kinase inhibitor, PR: partial response, SD: stable disease.

T854A, D761Y, and L747S, have been reported, but the number of cases were small $[14,24,25]$. The present study did not detect second-site EGFR mutations, besides T790M. In addition, our study did not detect acquired C797S mutation which mediates acquired resistance to third-generation EGFR TKI, AZD9291 although afatinib and AZD9291 both acts as an irreversible covalent inhibitor of the EGFR [26, 27]. More cases may be necessary to identify those rare second-site $E G F R$ mutations.

Small cell lung cancer transformation has been reported as a mechanism of acquired resistance to EGFR TKI, and it accounts for 3-14\% of cases who had acquired resistance to EGFR TKIs [9, 28]. A possible theory may be that both adenocarcinoma and small-cell lung cancer (SCLC) come from a common precursor, alveolar type II 
Table 2. Details of rebiopsy sites, tissue specimens and the prevalence of T790M

\begin{tabular}{|c|c|c|c|c|}
\hline Site & Procedure & Specimen No. & T790M (+) & Prevalence \\
\hline Right chest wall & echo-guided biopsy & 1 & 0 & $0 \%$ \\
\hline Mediastinum LN & VATS lymphadenectomy & 1 & 0 & $0 \%$ \\
\hline Right hip skin & Excisional biopsy & 1 & 0 & $0 \%$ \\
\hline $\mathrm{CSF}$ & lumbar puncture & 2 & 0 & $0 \%$ \\
\hline MPE & Thoracentesis & 18 & 8 & $44.4 \%$ \\
\hline Lung & $\begin{array}{l}6 \text { CT-guided biopsy } \\
7 \text { Echo-guided biopsy } \\
3 \text { Bronchoscopic brushing } \\
1 \text { Bronchoscopic biopsy } \\
1 \text { VATS lobectomy } \\
1 \text { autopsy }\end{array}$ & 19 & 12 & $63.2 \%$ \\
\hline
\end{tabular}

LN: lymph node, CSF: cerebrospinal fluid, MPE: malignant pleural effusion, CT: computer tomography, VATS: video-assisted thoracic surgery.

Table 3: Comparison of clinical characteristics between patients with acquired T790M and those without T790M

\begin{tabular}{|c|c|c|c|c|c|c|}
\hline & $\begin{array}{c}\text { All } \\
\text { patients }\end{array}$ & \multicolumn{2}{|c|}{$\begin{array}{c}\text { Acquired } \\
\text { T790M (+) }\end{array}$} & \multicolumn{2}{|c|}{$\begin{array}{c}\text { Acquired } \\
\text { T790M (-) }\end{array}$} & $p$ value \\
\hline Total No. & 42 & \multicolumn{2}{|c|}{$20(47.6 \%)$} & \multicolumn{2}{|c|}{$22(52.4 \%)$} & \\
\hline Age, median years & 57.5 & \multicolumn{2}{|c|}{58.2} & \multicolumn{2}{|c|}{54.5} & \multirow{2}{*}{$0.314^{\mathrm{a}}$} \\
\hline (range) & $(35.2-81.1)$ & \multicolumn{2}{|c|}{$(35.9-81.1)$} & \multicolumn{2}{|c|}{$(35.2-78.8)$} & \\
\hline Sex & & & & & & 0.952 \\
\hline Female & 25 & 12 & $(48.0 \%)$ & 13 & $(52.0 \%)$ & \\
\hline Male & 17 & 8 & $(47.1 \%)$ & 9 & $(52.9 \%)$ & \\
\hline Smoking & & & & & & $0.714^{*}$ \\
\hline Never-smokers & 33 & 15 & $(45.5 \%)$ & 18 & $(54.5 \%)$ & \\
\hline Smokers & 9 & 5 & $(55.6 \%)$ & 4 & $(44.4 \%)$ & \\
\hline Pre-afatinib & & & & & & 0.827 \\
\hline TKI-naïve & 14 & 7 & $(50.0 \%)$ & 7 & $(50.0 \%)$ & \\
\hline Prior TKI exposure & 28 & 13 & $(46.4 \%)$ & 15 & $(53.6 \%)$ & \\
\hline EGFR mutation & & & & & & 0.142 \\
\hline Del-19 & 14 & 9 & $(64.3 \%)$ & 5 & $(35.7 \%)$ & \\
\hline L858R & 22 & 10 & $(45.5 \%)$ & 12 & $(54.5 \%)$ & \\
\hline Others & 6 & $1^{\#}$ & $(16.7 \%)$ & 5 & $(83.3 \%)$ & \\
\hline Afatinib response & & & & & & $0.175^{*}$ \\
\hline PR & 37 & 16 & $(43.2 \%)$ & 21 & $(56.8 \%)$ & \\
\hline SD & 5 & 4 & $(80 / 0 \%)$ & 1 & $(20.0 \%)$ & \\
\hline
\end{tabular}

${ }^{*} \mathrm{~L} 861 \mathrm{Q}+\mathrm{T} 790 \mathrm{M}$.

*By Fisher exact test.

a'By Mann-Whitney $U$ test.

EGFR: epidermal growth factor receptor, Del-19: deletion in exon 19, TKI: tyrosine kinase inhibitor, PR: partial response, SD: stable disease. 
cells. When EGFR TKI blocks EGFR signaling related proliferation and differentiation of type II alveolar cells, these cells transform to SCLC if additional key genetic events such as RB1 inactivation occurs [29]. Although our study did not detect cases with SCLC transformation, identification of histological transformation via rebiopsy is still important because results may significantly alters treatment recommendations.
The study did not detect other known mutations in PIK3CA, BRAF, HER2, KRAS, NRAS, MEK1, AKT2, $L K B 1$ and $J A K 2$. Ohashi et al. identified acquired $B R A F$ mutation in $2(1 \%)$ patients from 195 tumor samples with acquired resistance to erlotinib [16]. Sequist et al. reported that acquired PIK3CA mutation was 5\% (2 of 37) [9]. The frequencies of acquired $P I K 3 C A$ and $B R A F$ mutations were very rare. It may result in undetected acquired
A

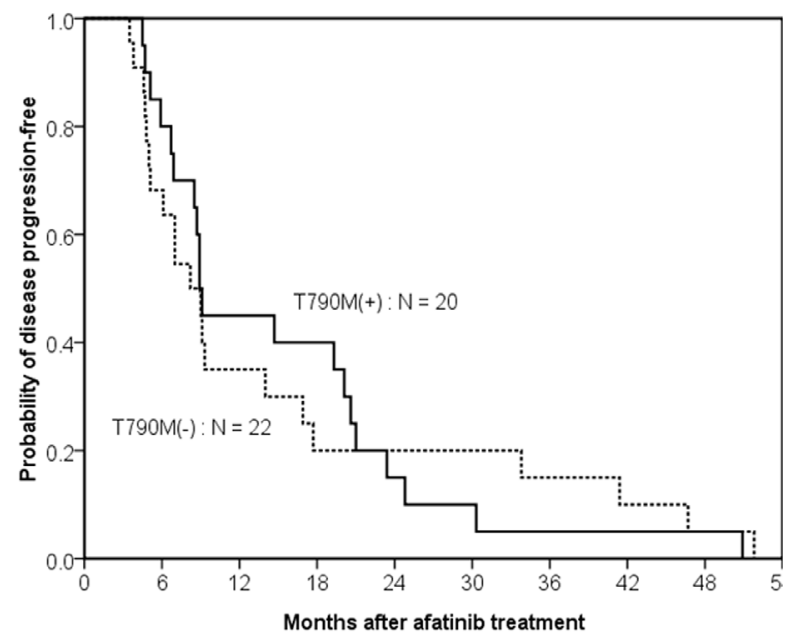

B

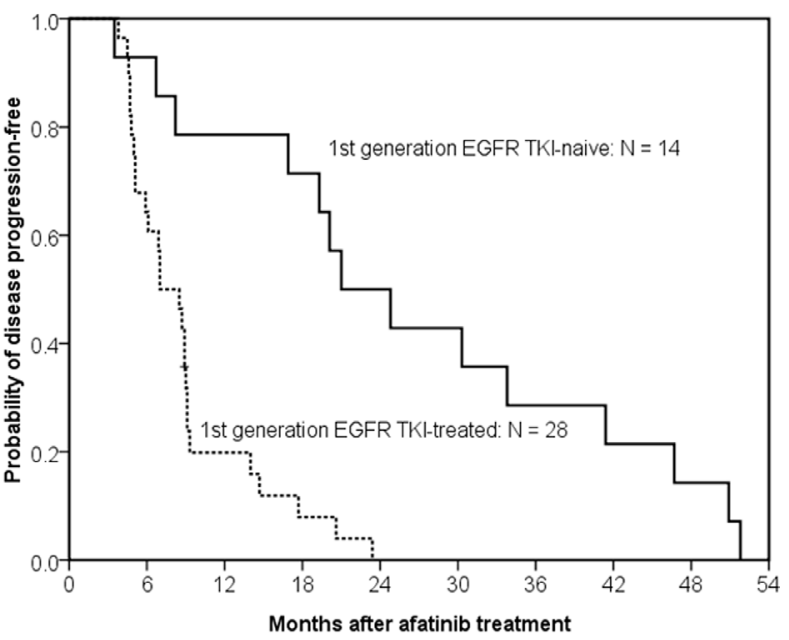

Figure 2: Kaplan-meier curve of afatinib progression-free survival in patients with acquired resistance to afatinib. (A) The difference in progression-free survival of afatinib treatment between patients with (solid line, $n=20$ ) and without acquired T790Mmutations (dashed line, $n=22$ ) did not reach statistically significant (median, 8.9 months vs. 8.2 months; $p=0.938$, by the log-rank test). (B) The difference in progression-free survival of afatinib treatment between first-generation EGFR TKI-naïve (solid line, $n=14$ ) and first-generation EGFR TKI-treated patients (dash line, $n=28$ ) reached statistically significant (median, 21.0 months vs. 7.0 months; $p<0.001$, by the log-rank test).

A

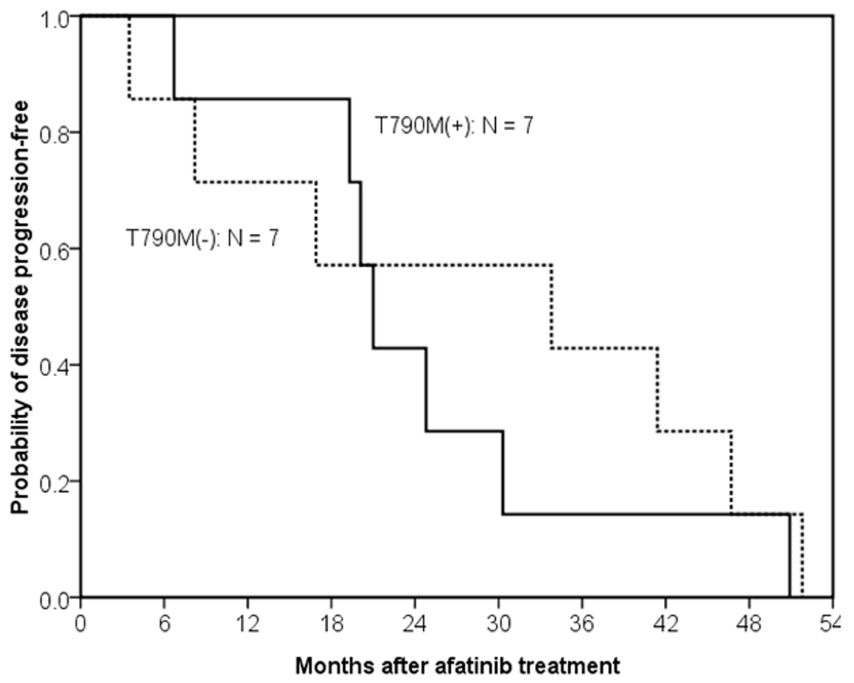

B

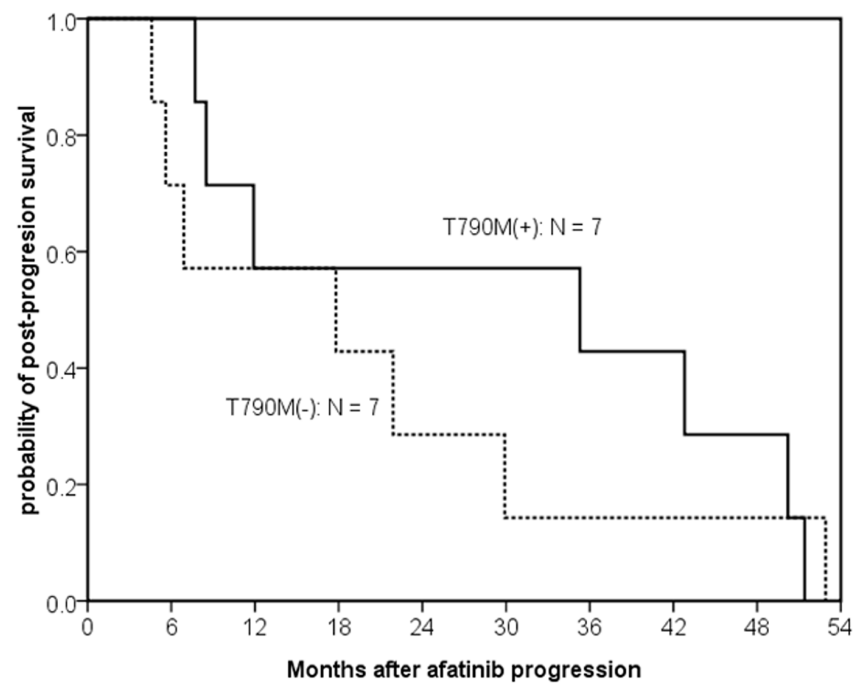

Figure 3: Kaplan-meier curve of post-afatinib-progression survival in 14 first-generation EGFR TKI-naïve patients who acquired resistance to afatinib. (A) The difference in progression-free survival between patients with (solid line, $n=7$ ) and without T790M-mutations (dashed line, $n=7$ ) did not reach statistically significant (median, 21.0 months vs. 33.8 months; $p=0.648$, by the log-rank test). (B) Patients with acquired T790M had a longer median post-afatinib-progression survival than patients without acquired T790M mutations, but the difference did not reach statistical significance (median, 35.3 months vs. 17.8 months; $p=0.616$, by the log-rank test). 
PIK3CA or BRAF mutation in the present study because of our small sample size.

Oxnard et al. showed that patients with T790M had significantly longer PPS [30]. Presence of T790M causes more indolent progression in lung cancer [30, 31]. The present study showed similar results, but the difference did not reach statistical significance. This may result from our small number of patients. More patients are necessary to confirm the result, especially in clinical practice.

Although secondary T790M is still the major mechanism of acquired resistance to afatinib, third-generation EGFR TKI, CO1686 (Rociletinib) and AZD9291, had promising treatment response for patients with resistance to EGFR-TKIs related to T790M mutation $[11,12]$, with about $60 \%$ of response rate and median progression free survival of 9.6-13.1 months [11, 12]. Therefore, finding EGFR T790M in tumor specimens after initial therapy with first- and second-generation EGFR TKIs is important to identify patients who may respond favorably to third-generation EGFR TKIs. Rebiopsy after disease progression may be indicated to guide future treatment plans based on different acquired resistance mechanisms.

This study had some limitations. First, the sample size was small although the present study has the largest patient number who had both pre- and post-afatinib tissue samples. However, obtaining tissue specimens for molecular analysis when patients experience disease progression is a persistent problem. Patients may be in extremely poor condition following initial TKI failure, and may not be suitable for rebiopsy. T790M detection from circulating cancer cells or cell-free DNA from blood might change the situation. Second, we did not analyze the amplifications of c-MET, HER2 or FGFR1 by fluorescence in situ hybridization because of the small quantity of specimens.

T790M was detected in half of lung adenocarcinoma with acquired resistance to afatinib. T790M is the major mechanism of acquired resistance to afatinib and those with acquired T790M mutations might benefit from the T790M-specific third-generation EGFR TKIs.

\section{MATERIALS AND METHODS}

\section{Patients and tissue procurement}

We retrieved afatinib-prescription records from the pharmacy department of National Taiwan University Hospital (NTUH) from January 2007 to December 2014. We enrolled afatinib-treated patients who had tissue specimens taken after acquiring resistance to afatinib. Patients included in the final analysis had to have both pre-afatinib and post-afatinib tumor specimens available for testing. This study was approved by the NTUH Research Ethics Committee. Some of the pre-afatinib samples were previously examined and reported [32].
The clinical characteristics and medical records were recorded, including demographic information and treatment courses. Patients who had smoked less than 100 cigarettes in their lifetime were categorized as never smokers [33]. Adenocarcinoma histology was confirmed either by pathology reports of the primary or metastatic tumors, or by cell blocks of malignant pleural effusion (MPE) with positive thyroid transcription factor-1 staining by immunocytochemistry [34].

We collected tumor specimens, including frozen tissues of surgical specimens, bronchoscopic or fine needle biopsies, and malignant pleural effusions. Written informed consent to use tissue for molecular analysis was obtained from patients at the time of specimen collection. Tissue sections were examined for adequacy by microscopy with hematoxylin and eosin staining.

\section{Acquired resistance to afatinib}

Categorization as acquired resistance to afatinib was modified from Jackman's criteria [35]. All patients received single-agent treatment with afatinib. They had both tumor harboring a TKI-sensitive EGFR mutation and objective treatment response, including partial response or durable stable disease (progression free survival [PFS] $\geq 6$ months) to treatment with afatinib. Response Evaluation Criteria in Solid Tumors (RECIST) version 1.1 was adapted to evaluate the objective treatment effect [36]. PFS was defined as days from the date of drug treatment until disease progression or death. Post-afatinib progression survival (PPS) was measured from the date of disease progression under afatinib treatment until the date of death.

First-generation EGFR TKI-naïve group was defined as patients receiving afatinib treatment without prior first-generation EGFR TKI exposure. Patients received prior first-generation EGFR TKIs treatment before taking afatinib were defined as first-generation EGFR TKI-treated group.

\section{Sequencing of EGFR exons 18-21}

Tissue specimens came from lung tumors, metastatic sites and malignant effusion cell blocks. The process of tissue specimen preparation for EGFR mutation analysis was as described previously $[37,38]$. RNA was extracted from different tissue specimens for gene mutation analysis with Qiamp RNA Mini Kit (Qiagen) according to the manufacturer's protocol. Spectrophotometry was used to quantify extracted RNA.

The cDNA was obtained from the extracted RNA by the Qiagen OneStep reverse transcription polymerase chain reaction (RT-PCR) kit (Qiagen). Exons 18-21 of $E G F R$ were amplified. The tyrosine kinase domain of the EGFR coding sequence, exons 18, 19, 20 and 21, were amplified with forward primer (5'- GGA- TCG- GCC- 
TCT- TCA- TGC-3') and reverse primer (5'-TAA-AATTGA-TTC-CAA-TGC-CAT-CC -3') by independent polymerase chain reaction (PCR) amplifications. The associated primers and conditions of RT-PCR have been revealed in our prior published reports [32, 39]. Finally, EGFR sequences of PCR amplicons were analyzed using ABI PRISM 3100 or 3700 (Applied Biosystems) in both sense and antisense directions.

\section{Sequencing of PIK3CA, BRAF, HER2, KRAS, NRAS, MEK1, AKT2, LKB1 and JAK2 mutation}

Genetic mutations of PIK3CA, HER2 and BRAF have been reported as the mechanism of acquired resistance to EGFR TKIs [9, 10]. In addition, other possible gene mutations were also studied in previous report, including, KRAS, NRAS and MEK1 [28]. After collection of the tissue specimens, we performed a series of genetic mutation analyses, including: $P I K 3 C A$, $B R A F$, HER2, KRAS, NRAS, MEK1, AKT2, LKB1 and $J A K 2$. Genes were amplified by RT-PCR using QIAGEN OneStep RT-PCR kit (Qiagen). The primers of the different genes were listed in the Supplementary Table S1.

RT-PCR conditions were based on manufacturer's protocol. PCR amplicons were sequenced using the same method described for EGFR mutation analysis.

\section{Statistical analysis}

Categorical variables were analyzed using Chi-square test. Univariate analysis of patient characteristics was used for comparison between post-afatinib T790M-positive and T790M-negative patients with acquired resistance to afatinib. PFS and PPS were plotted by the Kaplan-Meier method and compared by log-rank test. Two-sided $p$-values less than 0.05 were considered significant. SPSS software (version 17.0 for Windows; SPSS Inc.) was used for all analyses.

\section{ACKNOWLEDGMENTS}

The authors thank NTU Center for Genomic Medicine, National Taiwan University College of Medicine and the Office of Research and Development of NTUH for facility support and the pharmacy department of National Taiwan University Hospital for patient collection support.

\section{FUNDING}

This study was supported by grants NSC 101-2314-B-002 -167 -MY3 (National Science Council, Taiwan), 102-S2158, 103-FTN17, 104-S2675 (National Taiwan University Hospital, Taiwan), MOHW103-TDUPB-211-144002 (Ministry of Health and Welfare) and
NTUHYL 104.M001 (National Taiwan University, Y YunLin Branch, Yun-Lin, Taiwan).

\section{CONFLICTS OF INTEREST}

Dr. Yu, Dr. C-H Yang and Dr. Shih received honoraria for speeches from Astra Zeneca, Boehringer Ingelheim and Roche.

\section{REFERENCES}

1. Siegel R, Ma J, Zou Z, Jemal A. Cancer statistics, 2014. CA: a cancer journal for clinicians. 2014; 64:9-29.

2. Lynch TJ, Bell DW, Sordella R, Gurubhagavatula S, Okimoto RA, Brannigan BW, Harris PL, Haserlat SM, Supko JG, Haluska FG, Louis DN, Christiani DC, Settleman J, et al. Activating mutations in the epidermal growth factor receptor underlying responsiveness of non-small-cell lung cancer to gefitinib. The New England journal of medicine. 2004; 350:2129-2139.

3. Mok TS, Wu YL, Thongprasert S, Yang CH, Chu DT, Saijo N, Sunpaweravong $\mathrm{P}$, Han B, Margono B, Ichinose Y, Nishiwaki Y, Ohe Y, Yang JJ, et al. Gefitinib or carboplatinpaclitaxel in pulmonary adenocarcinoma. The New England journal of medicine. 2009; 361:947-957.

4. Zhou C, Wu YL, Chen G, Feng J, Liu XQ, Wang C, Zhang S, Wang J, Zhou S, Ren S, Lu S, Zhang L, Hu C, et al. Erlotinib versus chemotherapy as first-line treatment for patients with advanced EGFR mutation-positive nonsmall-cell lung cancer (OPTIMAL, CTONG-0802): a multicentre, open-label, randomised, phase 3 study. The Lancet Oncology. 2011; 12:735-742.

5. Mitsudomi T, Morita S, Yatabe Y, Negoro S, Okamoto I, Tsurutani J, Seto T, Satouchi M, Tada H, Hirashima T, Asami K, Katakami N, Takada M, et al. Gefitinib versus cisplatin plus docetaxel in patients with non-small-cell lung cancer harbouring mutations of the epidermal growth factor receptor (WJTOG3405): an open label, randomised phase 3 trial. The Lancet Oncology. 2010; 11:121-128.

6. Sequist LV, Yang JC, Yamamoto N, O'Byrne K, Hirsh V, Mok T, Geater SL, Orlov S, Tsai CM, Boyer M, Su WC, Bennouna J, Kato T, et al. Phase III study of afatinib or cisplatin plus pemetrexed in patients with metastatic lung adenocarcinoma with EGFR mutations. Journal of clinical oncology. 2013; 31:3327-3334.

7. Wu YL, Zhou C, Hu CP, Feng J, Lu S, Huang Y, Li W, Hou M, Shi JH, Lee KY, Xu CR, Massey D, Kim M, et al. Afatinib versus cisplatin plus gemcitabine for first-line treatment of Asian patients with advanced non-small-cell lung cancer harbouring EGFR mutations (LUX-Lung 6): an open-label, randomised phase 3 trial. The lancet oncology. 2014; 15:213-222.

8. Yang JC, Wu YL, Schuler M, Sebastian M, Popat S, Yamamoto N, Zhou C, Hu CP, O'Byrne K, Feng J, Lu S, Huang Y, Geater SL, et al. Afatinib versus cisplatin- 
based chemotherapy for EGFR mutation-positive lung adenocarcinoma (LUX-Lung 3 and LUX-Lung 6): analysis of overall survival data from two randomised, phase 3 trials. The Lancet Oncology. 2015; 16:141-151.

9. Sequist LV, Waltman BA, Dias-Santagata D, Digumarthy S, Turke AB, Fidias P, Bergethon K, Shaw AT, Gettinger S, Cosper AK, Akhavanfard S, Heist RS, Temel J, et al. Genotypic and histological evolution of lung cancers acquiring resistance to EGFR inhibitors. Science translational medicine. 2011; 3:75ra26.

10. Camidge DR, Pao W, Sequist LV. Acquired resistance to TKIs in solid tumours: learning from lung cancer. Nature reviews Clinical oncology. 2014; 11:473-481.

11. Janne PA, Yang JC, Kim DW, Planchard D, Ohe Y, Ramalingam SS, Ahn MJ, Kim SW, Su WC, Horn L, Haggstrom D, Felip E, Kim JH, et al. AZD9291 in EGFR inhibitor-resistant non-small-cell lung cancer. The New England journal of medicine. 2015; 372:1689-1699.

12. Sequist LV, Soria JC, Goldman JW, Wakelee HA, Gadgeel SM, Varga A, Papadimitrakopoulou V, Solomon BJ, Oxnard GR, Dziadziuszko R, Aisner DL, Doebele RC, Galasso C, et al. Rociletinib in EGFR-mutated non-small-cell lung cancer. The New England journal of medicine. 2015; 372:1700-1709.

13. Levin PA, Mayer M, Hoskin S, Sailors J, Oliver DH, Gerber DE. Histologic Transformation from Adenocarcinoma to Squamous Cell Carcinoma as a Mechanism of Resistance to EGFR Inhibition. J Thorac Oncol. 2015; 10:e86-88.

14. Costa DB, Halmos B, Kumar A, Schumer ST, Huberman MS, Boggon TJ, Tenen DG, Kobayashi S. BIM mediates EGFR tyrosine kinase inhibitor-induced apoptosis in lung cancers with oncogenic EGFR mutations. PLoS medicine. 2007; 4:1669-1679; discussion 1680.

15. Toyooka S, Date H, Uchida A, Kiura K, Takata M. The epidermal growth factor receptor D761Y mutation and effect of tyrosine kinase inhibitor. Clinical cancer research. 2007; 13:3431; author reply 3431-3432.

16. Ohashi K, Sequist LV, Arcila ME, Moran T, Chmielecki J, Lin YL, Pan Y, Wang L, de Stanchina E, Shien K, Aoe K, Toyooka S, Kiura K, et al. Lung cancers with acquired resistance to EGFR inhibitors occasionally harbor BRAF gene mutations but lack mutations in KRAS, NRAS, or MEK1. Proceedings of the National Academy of Sciences of the United States of America. 2012; 109:E2127-2133.

17. Kim Y, Ko J, Cui Z, Abolhoda A, Ahn JS, Ou S-H, Ahn M-J, Park K. The EGFR T790M Mutation in Acquired Resistance to an Irreversible Second-Generation EGFR Inhibitor. Molecular Cancer Therapeutics. 2012; 11:784-791.

18. Miller VA, Hirsh V, Cadranel J, Chen YM, Park K, Kim SW, Zhou C, Su WC, Wang M, Sun Y, Heo DS, Crino L, Tan EH, et al. Afatinib versus placebo for patients with advanced, metastatic non-small-cell lung cancer after failure of erlotinib, gefitinib, or both, and one or two lines of chemotherapy (LUX-Lung 1): a phase 2b/3 randomised trial. The Lancet Oncology. 2012; 13:528-538.
19. Kim Y, Ko J, Cui Z, Abolhoda A, Ahn JS, Ou SH, Ahn MJ, Park K. The EGFR T790M mutation in acquired resistance to an irreversible second-generation EGFR inhibitor. Mol Cancer Ther. 2012; 11:784-791.

20. Azuma K, Kawahara A, Sonoda K, Nakashima K, Tashiro K, Watari K, Izumi H, Kage M, Kuwano M, Ono M, Hoshino T. FGFR1 activation is an escape mechanism in human lung cancer cells resistant to afatinib, a pan-EGFR family kinase inhibitor. Oncotarget. 2014; 5:5908-5919. doi: 10.18632/oncotarget.1866.

21. Kobayashi S, Boggon TJ, Dayaram T, Janne PA, Kocher O, Meyerson M, Johnson BE, Eck MJ, Tenen DG, Halmos B. EGFR mutation and resistance of non-small-cell lung cancer to gefitinib. The New England journal of medicine. 2005; 352:786-792.

22. Pao W, Miller VA, Politi KA, Riely GJ, Somwar R, Zakowski MF, Kris MG, Varmus H. Acquired resistance of lung adenocarcinomas to gefitinib or erlotinib is associated with a second mutation in the EGFR kinase domain. PLoS medicine. 2005; 2:e73.

23. Kuiper JL, Heideman DA, Thunnissen E, Paul MA, van Wijk AW, Postmus PE, Smit EF. Incidence of T790M mutation in (sequential) rebiopsies in EGFR-mutated NSCLC-patients. Lung cancer. 2014; 85:19-24.

24. Balak MN, Gong Y, Riely GJ, Somwar R, Li AR, Zakowski MF, Chiang A, Yang G, Ouerfelli O, Kris MG, Ladanyi M, Miller VA, Pao W. Novel D761Y and common secondary T790M mutations in epidermal growth factor receptor-mutant lung adenocarcinomas with acquired resistance to kinase inhibitors. Clinical cancer research. 2006; 12:6494-6501

25. Bean J, Riely GJ, Balak M, Marks JL, Ladanyi M, Miller VA, Pao W. Acquired resistance to epidermal growth factor receptor kinase inhibitors associated with a novel T854A mutation in a patient with EGFR-mutant lung adenocarcinoma. Clinical cancer research. 2008; 14:7519-7525.

26. Thress KS, Paweletz CP, Felip E, Cho BC, Stetson D, Dougherty B, Lai Z, Markovets A, Vivancos A, Kuang Y, Ercan D, Matthews SE, Cantarini M, et al. Acquired EGFR C797S mutation mediates resistance to AZD9291 in nonsmall cell lung cancer harboring EGFR T790M. Nat Med. 2015; 21:560-562.

27. Solca F, Dahl G, Zoephel A, Bader G, Sanderson M, Klein C, Kraemer O, Himmelsbach F, Haaksma E, Adolf GR. Target Binding Properties and Cellular Activity of Afatinib (BIBW 2992), an Irreversible ErbB Family Blocker. Journal of Pharmacology and Experimental Therapeutics. 2012; 343:342-350.

28. Yu HA, Arcila ME, Rekhtman N, Sima CS, Zakowski MF, Pao W, Kris MG, Miller VA, Ladanyi M, Riely GJ. Analysis of tumor specimens at the time of acquired resistance to EGFRTKI therapy in 155 patients with EGFR-mutant lung cancers. Clinical cancer research. 2013; 19:2240-2247.

29. Oser MG, Niederst MJ, Sequist LV, Engelman JA. Transformation from non-small-cell lung cancer to small-cell lung cancer: molecular drivers and cells of origin. The Lancet Oncology. 2015; 16:e165-e172. 
30. Oxnard GR, Arcila ME, Sima CS, Riely GJ, Chmielecki J, Kris MG, Pao W, Ladanyi M, Miller VA. Acquired resistance to EGFR tyrosine kinase inhibitors in EGFRmutant lung cancer: distinct natural history of patients with tumors harboring the T790M mutation. Clinical cancer research. 2011; 17:1616-1622.

31. Hata A, Katakami N, Yoshioka H, Takeshita J, Tanaka K, Nanjo S, Fujita S, Kaji R, Imai Y, Monden K, Matsumoto T, Nagata K, Otsuka K, et al. Rebiopsy of non-small cell lung cancer patients with acquired resistance to epidermal growth factor receptor-tyrosine kinase inhibitor: Comparison between T790M mutation-positive and mutation-negative populations. Cancer. 2013; 119:4325-4332.

32. Wu SG, Yu CJ, Tsai MF, Liao WY, Yang CH, Jan IS, Yang PC, Shih JY. Survival of lung adenocarcinoma patients with malignant pleural effusion. The European respiratory journal. 2013; 41:1409-1418.

33. Centers for Disease $\mathrm{C}$ and Prevention. Cigarette smoking among adults-United States, 2006. MMWR Morb Mortal Wkly Rep. 2007; 56:1157-1161.

34. Travis WD, Brambilla E, Noguchi M, Nicholson AG, Geisinger KR, Yatabe Y, Beer DG, Powell CA, Riely GJ, Van Schil PE, Garg K, Austin JH, Asamura H, et al. International association for the study of lung cancer/ american thoracic society/european respiratory society international multidisciplinary classification of lung adenocarcinoma. J Thorac Oncol. 2011; 6:244-285.
35. Jackman D, Pao W, Riely GJ, Engelman JA, Kris MG, Janne PA, Lynch T, Johnson BE, Miller VA. Clinical definition of acquired resistance to epidermal growth factor receptor tyrosine kinase inhibitors in non-small-cell lung cancer. Journal of clinical oncology. 2010; 28:357-360.

36. Eisenhauer EA, Therasse P, Bogaerts J, Schwartz LH, Sargent D, Ford R, Dancey J, Arbuck S, Gwyther S, Mooney M, Rubinstein L, Shankar L, Dodd L, et al. New response evaluation criteria in solid tumours: revised RECIST guideline (version 1.1). European journal of cancer. 2009; 45:228-247.

37. Tsai TH, Su KY, Wu SG, Chang YL, Luo SC, Jan IS, Yu CJ, Yu SL, Shih JY, Yang PC. RNA is favourable for analysing EGFR mutations in malignant pleural effusion of lung cancer. The European respiratory journal. 2012; 39:677-684.

38. Tsai TH, Yang CY, Ho CC, Liao WY, Jan IS, Chen KY, Wang JY, Ruan SY, Yu CJ, Yang JC, Yang PC, Shih JY. Multi-gene analyses from waste brushing specimens for patients with peripheral lung cancer receiving EBUSassisted bronchoscopy. Lung cancer. 2013; 82:420-425.

39. Wu SG, Gow CH, Yu CJ, Chang YL, Yang CH, Hsu YC, Shih JY, Lee YC, Yang PC. Frequent epidermal growth factor receptor gene mutations in malignant pleural effusion of lung adenocarcinoma. The European respiratory journal. 2008; 32:924-930. 